ORIGINAL RESEARCH

\title{
Creating a new education paradigm to prepare nurses for the $21^{\text {st }}$ Century
}

\author{
Mary Bouchaud *, Denise Brown, Beth Ann Swan \\ Jefferson College of Nursing, Thomas Jefferson University, Philadelphia, United States
}

Received: April 5, 2017

Accepted: April 17, 2017

Online Published: May 2, 2017

DOI: $10.5430 /$ jnep.v7n10p27

URL: https://doi.org/10.5430/jnep.v7n10p27

\begin{abstract}
Nurse educators are accountable to keep baccalaureate education responsive to the ever changing healthcare delivery environment. The changing context of healthcare delivery requires focusing on population health and social determinants, providing interprofessional, team-based care, advancing innovation, and preparing practice ready baccalaureate nursing graduates. To be practice ready, nursing graduates must be agile and think and reason on their feet due to increasing care complexity beyond the hospital walls, changing care needs of individuals and families, advancing technology, shifting settings of care delivery, and managing multiple transitions. The purpose of this paper is to consider these healthcare changes and share a new baccalaureate nursing curriculum that radically shifts the paradigm from caring for patients to caring for people, and transforms from a diseased-based, acute care focused curriculum to one promoting a culture of health and multiple new and emerging roles of registered nurses.
\end{abstract}

Key Words: Baccalaureate nursing education, Curriculum innovation, $21^{\text {st }}$ century nursing practice, Innovation, Population health, Interprofessional

\section{INTRODUCTION}

The growing complex healthcare system is placing new challenges on healthcare providers in the $21^{\text {st }}$ century. These demands require a new education paradigm. This paradigm shift is supported by national reports and initiatives, and recognized in the lay business press. ${ }^{[1-3]}$ In addition, a Robert Wood Johnson Foundation (RWJF) Research Brief describes Nursing in a Transformed Health Care System, New Roles, New Rules. ${ }^{[4]}$ Trends in healthcare and nursing practice must be considered when educating new nurses. The purpose of this paper is to consider these healthcare changes and share a new baccalaureate nursing curriculum that radically shifts the paradigm from caring for patients to caring for people, and transforms from a diseased-based, acute care focused curriculum to one promoting a culture of health and multiple new and emerging roles of registered nurses.

\section{THE IDEAL BACCALAUREATE NURSING GRADUATE}

Baccalaureate and graduate faculty, students, and alumni, as well as community and practice partners, collaborated to design a curriculum that hones in on nurses' expanding roles as leaders in settings outside the acute care setting. The new baccalaureate curriculum was implemented at a College of Nursing within a large, urban academic health science university. The University's mission is Health is All We Do with a vision of reimagining health, health education and discovery to create unparalleled value, and values of innovation, service excellence, collaboration, ownership, respect, and empowerment. Consistent with the University's

\footnotetext{
*Correspondence: Mary Bouchaud; Email: mary.bouchaud@jefferson.edu; Address: Jefferson College of Nursing, Thomas Jefferson University, Philadelphia, United States.
} 
mission and vision, the College is dedicated to educating professional nurses who will form and lead the integrated healthcare delivery and research teams of tomorrow.

The College serves over 400 baccalaureate nursing students across three programs: traditional, FACT-2 year (full-time accelerated coursework track over two years), and FACT-1 year (full-time accelerated coursework track over 12 consecutive months). The traditional BSN program is designed for individuals with no prior nursing education and no bachelor's degree and enrolls students who have completed their first two years of pre-requisites courses (59 credits) at another institution. Students complete the program in two academic years. The FACT-1 year and FACT-2 year programs are designed for students with a bachelor's degree in a field other than nursing and 26 specific pre-requisites. The difference between the two options is the pace and length of time required to complete them.

The Dean of the College solicited nursing faculty interested in leading a team to reimagine baccalaureate nursing education. Interested faculty provided a letter to the Dean identifying their interest in participating in this new challenge including the skills that they would bring to such a unique team and the personal gains they hoped to achieve. Eight undergraduate and one graduate faculty along with one university hospital affiliate practice partner were selected for the core team who collectively named themselves the Curriculum Navigators (CNs). The CNs then invited a current student, an alumnus, a clinical faculty, a community partner, and an individual receiving care through the University's health system to join the CNs.

Beginning with a blank slate, faculty leading the design of the new curriculum (known as the Curriculum Navigators) explored the ideal characteristics and skill set of a baccalaureate nursing graduate with faculty, current students, alumni, and practice and community partners. From the beginning, the CNs saw their role as organizing and navigating the change process, not dictating the content of the curriculum. Despite the project's aggressive timeline of 13 months (April 2014 to May 2015), the CNs were committed to involving all nursing faculty and obtaining their expertise, ideas, and feedback throughout the process.

\subsection{Faculty participation}

Faculty members were engaged during eight general faculty meetings. During the first meeting, the CNs asked faculty, "How do employers, the public, professional colleagues, faculty, and the community identify the University's professional registered nurses (RNs) from other new graduates and RNs? What characteristics, behaviors, and/or competencies would that end product possess after completing the University's BSN program?” In addition, faculty were queried regarding the "hot topics" in healthcare delivery and nursing practice today, and asked to identify new knowledge, skills, competencies, and nursing issues and trends that should be included in a futuristic curriculum. Faculty quickly responded to the challenge by documenting their responses on individual post-it notes and placing them on posters throughout the room. Without direction, faculty began rearranging post-it notes to depict a visual schematic of emerging themes. Faculty members were vocal regarding the need for the $\mathrm{CNs}$ to ensure the integrity of their proposed responses through ongoing review of literature and national reports to validate an evidence-based curriculum.

\subsection{Student participation}

During a class on nursing issues and trends, senior nursing students were assigned an in-class group activity requiring them to present their reflective analysis of three questions pertaining to designing a new curriculum: 1) students were asked to define the skill set that they believed they bring to an employer (no definition of skill set was provided so as to not limit the students' exploration and discussion), 2) how they, as a contemporary RN of the 21 st century, would improve the disparity of access to healthcare that many individuals and families experience, and 3) where did they see themselves in their nursing career in the next five years. Students then presented their in-class group responses to the class in creative posters. Student responses' related to skill set included knowledge, interpersonal communication, technical/clinical competencies, interprofessional leadership, evidence-based care, individual and family education, primary prevention, advocacy, and therapeutic communication. Students cited expertise in the use of technology related to documentation as a skill to access clinical information. In addition, students proudly shared that they bring an employer and the nursing profession characteristics such as resilience, determination, flexibility, time management, diversity awareness, innovative ideas, and confidence.

\subsection{Alumni and practice partner participation}

The CNs also completed focus groups with alumni and practice partners, to gain information about their experience as new to practice nurses (alumni) and their experience with the College's new graduate nurses (practice partners). The alumni group included individuals who recently graduated, as well as those practicing for one to five years as RNs in inpatient, outpatient, or community settings. The practice partners group included individuals such as nurse managers and staff nurses from acute care hospitals, as well as individuals from home health and community agencies where 
students currently complete their clinical rotations. Surprisingly, alumni and practice partners identified the following common qualities: 1) emotional intelligence, 2) social awareness, 3) clinical competence, 4) cultural awareness, 5) critical thinking, 6) adaptability, 7) self-awareness, 8) professionalism, 9) interprofessional leadership, and 10) innovative thinking. Following these focus groups, students, alumni, and practice partners continued to be involved in developing the curriculum through their representatives on the $\mathrm{CN}$ team.

\section{Curriculum design}

With the ideal nursing graduate created, CNs aligned all this information with a curriculum centered on humanism (referring to person-centered care and the humanistic narrative of a person seeking healthcare), evidence-based education and practice, reflective analysis and evaluation, and leadership and professionalism in practice. The curriculum's organizing framework statement positioned health and quality of life along the health-illness care continuum. The organizing framework statement definition was developed guided by the nursing metaparadigm - person, environment, health, and nursing, the University's mission, vision, and values previously described, and the American Association of Colleges of Nursing's (AACN) Essentials of Baccalaureate Education for Professional Nursing. ${ }^{[5]}$ The organizing framework statement addressed three continuums: 1) lifespan, 2) state of health, and 3) care transitions. Considering these three continuums, as well as the ideas gleaned from faculty, students, alumni, practice partners, and environmental scans of exist- ing literature, working papers, government, regulatory, and advisory body reports, four themes emerged: 1) population health, 2) interprofessional collaboration, 3) innovation, and 4) practice excellence. ${ }^{[6]}$

\subsection{End of program outcomes and level competencies}

The end of program outcomes were formed by all the information and data collected from stakeholders, as well as the tables of evidence. Synthesis of all the collected information and data revealed that the ideal graduate would have the knowledge, skills, competencies, and attitudes necessary to practice in any care setting they found themselves in as new graduate nurses (acute care, ambulatory care, or transitional setting). From the draft end of program outcomes, competencies for each semester (for traditional and FACT-2 year students) and each quarter (for FACT-1 year students) were developed, progressing from simple to complex. Once the CNs drafted the end of program outcomes and level competencies, general faculty reviewed them during an allday workshop and provided feedback on the draft outcomes, proposed learning experiences to operationalize each level competency increasing in complexity, and proposed evaluation methods for each level competency. From the final end of program outcomes, leveled competencies were created for each of the four semesters/quarters of the curriculum, with each level increasing in complexity and building to the final senior semester/quarter level. End of program outcomes are listed in Table 1 and an example of senior level competencies is described in Table 2 .

Table 1. End of program outcomes

- $\quad$ Synthesize knowledge of the arts, science, and humanities to address the developmental, psychosocial, spiritual, and physical needs of individuals and their families.

- Demonstrate responsibility and accountability within the legal, ethical, and regulatory guidelines of the nursing profession.

- $\quad$ Assume a leadership role within nursing and interprofessional health care teams.

- Use the scientific process, critical thinking, and creative problem-solving consistent with both reflective and evidence-based practice for clinical decision making.

- Demonstrate a commitment to innovative practice for providing safe and quality care to individuals and their families across the care continuum.

- $\quad$ Coordinate care and transitions across providers and settings.

- Apply communication and emerging technologies to nursing practice for optimal outcomes.

- Incorporate population health in nursing practice.

- $\quad$ Advocate for effective social and health policies at local, state, national, and international levels.

- $\quad$ Support and engage in nursing and health care research.

\subsection{Concept identification}

Curriculum design began with the CNs developing a list of approximately 53 concepts identified in the literature and national reports and linked each concept to the four curricular themes - interprofessional collaboration, population health, innovation, and practice excellence. Guided by each theme, Published by Sciedu Press several curricular elements were identified and became central concepts of the curriculum and facilitated organization of content. The next step was identifying exemplars based on interrelated concepts and then titles for individual courses were drafted based on themes and concepts, followed by a draft plan and sequencing of courses. 
Table 2. Level competencies: Semester 4/Quarter 4

\begin{tabular}{|c|c|}
\hline Level Four & Semester 4/Quarter 4 \\
\hline $4-1$ & $\begin{array}{l}\text { Recognize the relationships of health and illness as they relate to biological, psychosocial, and developmental theories. } \\
\text { Differentiate developmental and psychosocial skills of inquiry, analysis, and information technology to address issues in nursing } \\
\text { practice. } \\
\text { Develop a collaborative plan of care using findings from patient and family health assessments influenced by developmental, } \\
\text { psychosocial, spiritual and physical needs. }\end{array}$ \\
\hline $4-2$ & Act as an advocate for patients, families and populations within the legal, ethical, and regulatory guidelines of the nursing profession. \\
\hline $4-3$ & $\begin{array}{l}\text { Combine leadership, clinical reasoning, decision making and communication skills to effectively implement patient safety and quality } \\
\text { improvement initiatives within the context of the interprofessional team. } \\
\text { Choose effective communication techniques to promote positive interprofessional working relationships. } \\
\text { Lead appropriate team building and collaborative strategies when working with inter-professional teams. }\end{array}$ \\
\hline 4-4 & Synthesize the scientific process, evidence, critical thinking, and creative problem solving to support clinical decision-making. \\
\hline $4-5$ & $\begin{array}{l}\text { Integrate critical, systematic, and innovative thinking to enhance safe quality person centered care across the care continuum. } \\
\text { Integrate technologies that support clinical decision-making, error prevention, and care coordination. }\end{array}$ \\
\hline $4-6$ & $\begin{array}{l}\text { Evaluate/modify plans of care for patients/families. } \\
\text { Initiate care coordination and transitions for patients/families. }\end{array}$ \\
\hline $4-7$ & Initiate effective communication skills with patients/families and the interprofessional team. \\
\hline $4-8$ & $\begin{array}{l}\text { Collaborate with a community partner and interprofessional team to develop a intervention plan that incorporates a population health } \\
\text { perspective. } \\
\text { Evaluate population health interventions aimed at improving a community's health. } \\
\text { Consider recommendations for improvement of current population health interventions. }\end{array}$ \\
\hline $4-9$ & $\begin{array}{l}\text { Advocate for patients/families in meeting their health goals. } \\
\text { Incorporate knowledge from social and health policies from the local, state, national and international level into plans of care. }\end{array}$ \\
\hline $4-10$ & $\begin{array}{l}\text { Actively support research through collection, documentation, and dissemination of evidence. } \\
\text { Apply the principles of research in practice settings in order to directly affect patient outcomes. }\end{array}$ \\
\hline
\end{tabular}

\subsection{Individual course syllabi: Planning and sequencing}

Once the level competencies were finalized, CNs developed competency learning progression maps and this guided the drafting, planning, and sequencing of proposed course titles and syllabi. The CNs drafted syllabi including course title, course objectives, content outlines, and proposed evaluation methods that reflected curricular themes, end of program outcomes, level competencies, and most importantly the plan of study needed to realize the vision of the College - educating professional registered nurses who will form and lead the integrated healthcare delivery and research teams for the $21^{\text {st }}$ century - a change agent capable of fostering a new culture of health. ${ }^{[6]}$ The plan of study addressed the ideal foundational skill set so that graduates would be prepared to provide care across transitions; care for people along the healthcare continuum in settings such as primary care, ambulatory care, home, community; and other "outside the box" settings such as shelters, churches, and libraries to name a few. Experiential learning and service learning opportunities were included in the new curriculum, and clinical rotations were renamed as immersion experiences. The CNs transformed traditional clinical rotations into five new, innovative immersion experiences so that students have the opportunity to experience the care continuum each week. For example, one day, a student may be on an acute care oncology unit and the second day, have an immersion experience in an ambulatory setting such as an outpatient infusion center or oncology ambulatory care practice. Immersion experiences are across the lifespan and across the care continuum. With a focus on wellness and health promotion, population health and disease prevention, faculty also changed the notion of patient-centered care to person-centered care to highlight that the curriculum needed to teach nursing students and RNs that they are working with/partnering with people not patients.

\subsection{Concept/content maps}

To ensure precision of the level competencies and end of program outcomes, another set of competency learning progression maps were developed to identify gaps in courses and guide revision and updating of course syllabi. The updated course syllabi were shared with all faculty members and consensus was achieved through faculty members sharing their opinions and suggestions, in an atmosphere of cooperation, and reaching agreement during a faculty meeting. The course objectives, level outcomes, and end of program outcomes were mapped to the Essentials of Baccalaureate Education for Professional Nursing, Quality and Safety Education for Nurses (QSEN) competencies, Core Competencies for Interprofessional Collaborative Practice, and the Clinical Prevention and Population Health Curriculum Framework. ${ }^{[5,7-9]}$ The plans of study for traditional, Fact-2 year, and FACT-1 year are depicted in Table 3. 
Table 3. Baccalaureate nursing plan of study for traditional, FACT-2 year, and FACT-1 year students

\begin{tabular}{|c|c|c|c|c|c|}
\hline \multicolumn{6}{|c|}{ Traditional Plan of Study } \\
\hline \multirow{2}{*}{\multicolumn{3}{|c|}{$\begin{array}{l}\text { Junior Year } \\
\text { Level I }\end{array}$}} & \multirow{2}{*}{\multicolumn{3}{|c|}{$\begin{array}{l}\text { Senior Year } \\
\text { Level III }\end{array}$}} \\
\hline & & & & & \\
\hline & Credit & Course Name & & Credit & Course Name \\
\hline 330 & 0 & Bridge for Success (7 wks) & 415 & 3 & Care Coordination and Care Transitions \\
\hline 315 & 3 & Health Assessment Across Lifespan & 416 & 3 & Population Health and Health Disparities \\
\hline 307 & 3.5 & Foundations in Nursing (1st 7 wks) & 417 & 4.5 & Health Promotion Across the Lifespan III \\
\hline 308 & 1.5 & Introduction to Pharmacology & 419 & 2 & Professional Practice III \\
\hline 317 & 3 & Health Promotion Across the Lifespan (2nd 7 wks) & 428 & 4 & Immersion III \\
\hline 319 & 2 & Professional Practice I & & & \\
\hline 328 & 2 & Immersion I (2nd 7wks) & & & \\
\hline \multicolumn{3}{|c|}{ Level II } & \multicolumn{3}{|c|}{ Level IV } \\
\hline 318 & 4.5 & Health Promotion Across the Lifespan II & 418 & 3 & Clinical Reasoning \\
\hline 320 & 2 & Professional Practice II & 420 & 3 & Professional Practice IV \\
\hline 329 & 4 & Immersion II & 429 & 2.5 & Selected Immersion (7 wks) \\
\hline 327 & 3 & Healthcare Informatics \& Innovation & 430 & 2.5 & Advanced Immersion (7 wks) \\
\hline \multirow[t]{2}{*}{326} & \multirow[t]{2}{*}{3} & \multirow[t]{2}{*}{ Discovery \& Evidence-based Practice } & 498 & 3 & $\begin{array}{l}\text { Promoting Health \& Quality of life along the Care } \\
\text { Continuum (selective) }\end{array}$ \\
\hline & & & 435 & 2 & NCLEX Prep for Success (2nd 7 wks) \\
\hline \multicolumn{6}{|c|}{ FACT-2 Year Plan of Study } \\
\hline \multirow{2}{*}{\multicolumn{3}{|c|}{$\begin{array}{l}\text { Junior Year } \\
\text { Semester I }\end{array}$}} & \multirow{2}{*}{\multicolumn{3}{|c|}{$\begin{array}{l}\text { Senior Year } \\
\text { Semester III }\end{array}$}} \\
\hline & & & & & \\
\hline & Credit & Course Name & & Credit & Course Name \\
\hline 330 & 0 & Bridge for Success (7 wks) & 415 & 3 & Care Coordination and Care Transitions \\
\hline 315 & 3 & Health Assessment Across Lifespan & 416 & 3 & Population Health and Health Disparities \\
\hline 307 & 3.5 & Foundations in Nursing (1st 7 wks) & 417 & 4.5 & Health Promotion Across the Lifespan III \\
\hline 308 & 1.5 & Introduction to Pharmacology & 419 & 2 & Professional Practice III \\
\hline 317 & 3 & Health Promotion Across the Lifespan (2nd 7 wks) & 428 & 4 & Immersion III \\
\hline 319 & 2 & Professional Practice I & & & \\
\hline 328 & 2 & Immersion I (2nd 7wks) & & & \\
\hline \multicolumn{3}{|c|}{ Semester II } & \multicolumn{3}{|c|}{ Semester IV } \\
\hline 318 & 4.5 & Health Promotion Across the Lifespan II & 418 & 3 & Clinical Reasoning \\
\hline 320 & 2 & Professional Practice II & 420 & 3 & Professional Practice IV \\
\hline 329 & 4 & Immersion II & 429 & 2.5 & Selected Immersion (7 wks) \\
\hline 672 & 3 & Informatics (graduate) & 430 & 2.5 & Advanced Immersion (7 wks) \\
\hline \multirow[t]{2}{*}{609} & 3 & Research for APN I (graduate) & 625 & 3 & Epidemiology (graduate) \\
\hline & & & 435 & 2 & NCLEX Prep for Success (2nd 7 wks) \\
\hline \multicolumn{6}{|c|}{ FACT-1 Year Plan of Study } \\
\hline \multirow{2}{*}{\multicolumn{3}{|c|}{$\begin{array}{l}\text { Junior Year } \\
\text { Quarter I }\end{array}$}} & \multicolumn{3}{|c|}{ Senior Year } \\
\hline & & & Qua & r III & \\
\hline & Credit & Course Name & & Credit & Course Name \\
\hline 330 & 0 & Bridge for Success (7 wks) & 415 & 3 & Care Coordination and Care Transitions \\
\hline 315 & 3 & Health Assessment Across Lifespan & 416 & 3 & Population Health and Health Disparities \\
\hline 307 & 3.5 & Foundations in Nursing (1st 7 wks) & 417 & 4.5 & Health Promotion Across the Lifespan III \\
\hline 308 & 1.5 & Introduction to Pharmacology & 419 & 2 & Professional Practice III \\
\hline 317 & 3 & Health Promotion Across the Lifespan (2nd 7 wks) & 428 & 4 & Immersion III \\
\hline 319 & 2 & Professional Practice I & & & \\
\hline 328 & 2 & Immersion I (2nd 7wks) & & & \\
\hline Qua & r II & & Qua & r IV & \\
\hline 318 & 4.5 & Health Promotion Across the Lifespan II & 418 & 3 & Clinical Reasoning \\
\hline 320 & 2 & Professional Practice II & 420 & 3 & Professional Practice IV \\
\hline 329 & 4 & Immersion II & 429 & 2.5 & Selected Immersion (7 wks) \\
\hline 672 & 3 & Informatics (graduate) & 430 & 2.5 & Advanced Immersion (7 wks) \\
\hline 609 & 3 & Research for APN I (graduate) & 625 & 3 & Epidemiology (graduate) \\
\hline & & & 435 & 2 & NCLEX Prep for Success (2nd 7 wks) \\
\hline
\end{tabular}


Simultaneously, the CNs completed a review of the literature related to teaching-learning theory and best practice strategies to achieve qualities of the ideal baccalaureate nursing graduate. Literature included constructivism education theory, concept-based learning, problem-based learning, and other trends related to nursing education. Evidence revealed the importance of teaching conceptually. ${ }^{[10]}$ This information was shared with the faculty and a decision was made to move forward with a concept-based curriculum.

\section{IMPLEMENTATION DESIGN}

Once the new concept-based curriculum was approved by the faculty, the College's Executive Council, and the State Board of Nursing, the implementation design process began. The first step was identifying the implementation design team. Although the CNs had overseen the development of the curriculum, the need existed for a team (subset of the $\mathrm{CNs}$ ) to move implementation forward. Four members of the CNs volunteered to be the Implementation Design Team (IDT) and met regularly beginning in June 2015 to oversee the process. The plan was to offer the new curriculum to the May 2016 FACT-1 year cohort (128 students) and the Fall 2016 traditional cohort (160 students). The IDT invited all faculty members to participate in the process by joining four subcommittees of the IDT: 1) immersion planning, 2) immersion evaluation, 3) weighted measures, and 4) progression policy. The subcommittees were led by three members of the IDT and one other faculty member. The immersion planning group looked at incorporating new transitional sites into the students' immersion experiences, and worked to create new clinical reasoning tools to replace the old clinical assignments. The immersion evaluation group was responsible for developing a new immersion evaluation tool. Since the immersion experiences would be different than the traditional clinical experience, the faculty felt a new evaluation tool should be developed. The weighted measures group was responsible for overseeing the weighting of the new course assignments. Lastly, the progression policy group looked at the existing policy to identify changes that were needed for the concept-based curriculum. Faculty also worked in small groups to further develop the new course syllabi, adding teaching-learning strategies and developing course assignments. The syllabi were then reviewed by four faculty members who had expertise in pedagogy, course and curriculum design, teaching-learning strategies, and evaluation methods. Following their review, course syllabi were reviewed and approved by the faculty.

During the implementation design phase, faculty identified four areas for further exploration: 1) active learning, 2) student academic support, 3) service learning and experiential learning, and 4) competency achievement. Faculty members felt strongly about adopting active learning defined as a process whereby students engage in activities that promote analysis, synthesis, and evaluation of class content and requires preparing for class, participating in class, collaborating with each other, and applying a concept to a real-world situation.

In addition, faculty members were committed to identifying resources for working with all students within the new curriculum, as well as "at risk" students. Faculty recommended creating an orientation program to prepare students for a rigorous nursing program and new ways of thinking. Student academic support offerings are described in Table 4 and definitions for service learning and experiential learning are listed in Table 5.

Table 4. Student academic support

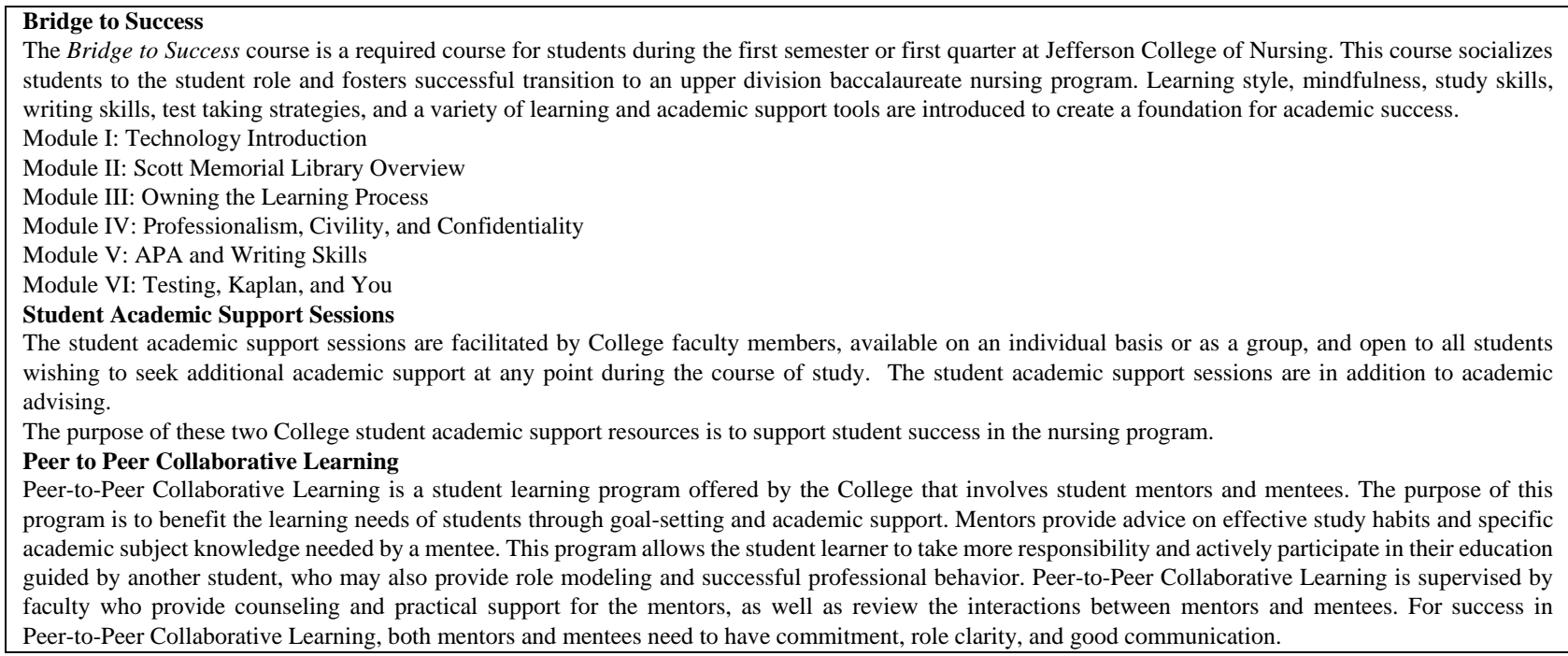


Table 5. Definitions for service learning and experiential learning

Service Learning: Meaningful service to a community, group, organization, or population in combination with academic teaching and learning. Service experiences are incorporated into coursework and require students to participate in projects specific and valuable to an organization group, or population while enhancing the student's understanding of course content. ${ }^{[1]}$

Experiential Learning: Opportunities that provided students with carefully selected activities in "real world" settings to practice and enhance their skills by assuming responsibility for problem-solving and decision making. Students engage in reflection that will enable them to analyze and synthesize their experiences and acquire new knowledge. ${ }^{[12]}$

The goal of service learning is to provide students with an understanding of the impact of individual and family circumstances on the ability to access health care, and one's readiness and capacity to participate in care, as well as manage one's own health. ${ }^{[11]}$ The experience may focus on obtaining a better understanding of health equity and disparity, as well as social determinants. Service learning opportunities focus on real-world application of population health concepts, civic engagement, health outcomes, health and social policy, leadership and advocacy, financing and economics, and community-academic partnerships. Experiential learning opportunities emphasize coordinating care and managing transitions, and the role of the registered nurse within a teambased care model. Experiential learning opportunities focus on real-world application of care coordination and transition management concepts, activation and engagement of individuals and families, implications of health policy and financing on care coordination and care transitions. ${ }^{[12]}$ These opportunities take place within didactic courses, not immersion experiences.

Finally, faculty wanted to create a "space" where students could submit on an ongoing basis, examples of achievement of individual course outcomes, level competencies, and end of program outcomes. Students were provided with a digital platform in the form of an electronic portfolio to collect evidence in support of their academic and professional achievements. Students share the content with whom they would like to share it within their academic program. Students are able to design, manage, and individualize their own collection of academic, immersion, and real life experiences. The electronic portfolio's strength lies in its capability to support and engage students while providing them with a professional platform for life, while simultaneously demonstrating learning, skills, competencies, and job-placement outcomes. ${ }^{[13]}$ Students as new nurse graduates are now able to provide prospective employers visible evidence of their knowledge, skills, and competencies. Employers are able to consider the significance of a student's work in communicating skills and knowledge through the related artifacts that are included in the portfolio. Some examples of artifacts include: 1) entries describing experiences with team-based competencies of values/ethics, roles/responsibilities, commu-

Published by Sciedu Press nication, and interprofessional process; 2) entries explaining and reflecting upon their service learning and experiential learning experiences; 3 ) selected evaluation methods from each course; 4) service learning concept map development project; and 5) survey results of community assessment.

\section{FACULTY DEVELOPMENT}

Faculty development was extremely important to the implementation design process, as the faculty had minimal to no experience teaching in a concept-based curriculum. Several workshops led by experts in concept-based teaching and learning were held for the general faculty. In addition, faculty worked with their colleagues in the Center for Teaching and Learning, one-on-one and in groups, to create active learning lesson plans. In-person and virtual workshops were also held for the clinical adjunct faculty, now known as immersion educators, explaining the new curriculum, the expectations of the immersion experiences and the new clinical reasoning tools. Faculty also worked with the clinical partners to keep them abreast of the changes. There was also a need to evolve the role of clinical adjunct faculty to immersion educators. Community and practice partners needed to be educated about the changing education paradigm and shifting immersion teaching-learning expectations in the new curriculum. Investment in ongoing faculty development was required for current and newly hired full-time faculty to augment active teaching-learning strategies in the classroom; acquire knowledge, skills, and competencies in concept-based teaching and learning; and create new immersion evaluation tools. In addition, faculty needed to develop a plan for teaching the last class of students enrolled in the legacy curriculum, while beginning the new H.E.R.E. (Humanistic, Evidence-based, Reflective, Excellence in clinical leaders) concept-based curriculum. Considerations for simultaneously teaching two curriculums are described in Table 6.

\section{IMPLEMENTATION EVALUATION}

Once implementation design concluded in May 2016, the IDT believed there was a need for an implementation evaluation team (IET). Five faculty members volunteered to be part of the IET, none of whom were on the CNs or the IDT. This team focused on 1) reviewing the concept and exemplar 
maps for redundancy and omissions, 2) evaluating faculty members' adaptation to teaching a concept based curriculum, and 3) reviewing progression policy. The IET will make recommendations to the faculty for potential changes. For the 2017-2018 academic year, the IET will continue the evaluation process as IET 2.0. The legacy curriculum will have concluded, the 2016-2017 accelerated cohort will have graduated, the 2017-2018 accelerated cohort will be in their second quarter, the 2016-2018 traditional cohort will be se- niors, and the 2017-2019 traditional cohort will begin. The IET 2.0 will continue to monitor the implementation process and also analyze NCLEX-RN scores of the 2017 graduates from the legacy and H.E.R.E. curriculums. A comparison of graduation rates, attrition rates, and exit survey results will be assessed to determine whether the College's vision for the professional registered nurse of the 21 st century is being realized.

Table 6. Additional (and Simultaneous) considerations

\begin{tabular}{|c|c|}
\hline Legacy Curriculum & H.E.R.E. Concept-based Curriculum \\
\hline Plan for teaching last class of students enrolled in legacy curriculum. & $\begin{array}{l}\text { Some faculty members teaching simultaneously in legacy } \\
\text { curriculum and H.E.R.E. curriculum. }\end{array}$ \\
\hline Identifying clinical experiences. & $\begin{array}{l}\text { Identifying new immersion experiences, as well as service } \\
\text { learning and experiential learning opportunities. }\end{array}$ \\
\hline Hiring clinical adjunct faculty. & $\begin{array}{l}\text { Hiring new immersion educators and providing professional } \\
\text { development about new role. }\end{array}$ \\
\hline $\begin{array}{l}\text { Plan for progression for students not successful in one course (grade of } \\
77 \text { or higher) required faculty to teach these repeated courses. Also } \\
\text { needed to offer a summer school option for any student who was not } \\
\text { successful in one course in the final semester. }\end{array}$ & $\begin{array}{l}\text { New academic progression policy, if a student is not successful } \\
\text { in one course (any course), student will be dismissed from the } \\
\text { program. }\end{array}$ \\
\hline
\end{tabular}

\section{ENGAGING STUDENTS}

As part of the new H.E.R.E. curriculum, the College created the H.E.R.E. Fellows program. All accepted students were sent a letter and invited to apply. The letter explained the new forward thinking, baccalaureate nursing curriculum, and that the Fellows program was highly selective and recognized and honored the accepted student's accomplishments. H.E.R.E. Fellows receive a $\$ 10,000$ scholarship, have the opportunity to participate in the Dean's Dialogue Series, can distinguish themselves in the pursuit of academic excellence by serving as student leaders in the peer-to-peer collaborative learning program, and be recognized during the Class Day event prior to commencement.

The scholarship is renewable for students' senior year. A committee selected the Fellows based solely on the quality of their essay of at least 250 words answering the question: "How will the H.E.R.E. curriculum support my leadership development and future career as a professional nurse?" Seventy (70) Fellows were selected across all the baccalaureate programs.

\section{REFERENCES}

[1] Institute of Medicine (IOM). The future of nursing leading change, advancing health. Washington, DC: The National Academies Press; 2011.

\section{SUMMARY}

Creating a new baccalaureate nursing curriculum is a daunting undertaking that requires buy-in and collaborative efforts of faculty, students, alumni, practice partners, and community stakeholders. The value of ground rules such as: 1) transparency among all stakeholders, 2) open and frequent evidence-based dialogue among stakeholders via multiple, creative approaches, and 3) an open door policy between College leadership and various design and implementation teams cannot be underestimated. Measures such as these can minimize obstacles and thwart escalations of frustration. With any newly implemented curriculum, it may take several years to fully implement, evaluate, and update to the point where faculty, students, and stakeholders are satisfied. Even then, there is a critical need for continuous quality improvement.

\section{ACKNOWLEDGEMENTS}

The authors acknowledge the vision and dedication of the Curriculum Navigators.

\section{Conflicts OF InTEREST Disclosure}

The authors declare that there is no conflict of interest.

[2] Japsen B. Nurse jobs shift from the hospital to the community. Forbes. 2015.

[3] Josiah Macy Jr. Foundation. Registered nurses: Partners in transforming primary care. Recommendations from the Macy Foundation 
Conference on Preparing registered nurses for enhanced roles in primary care. 2016. Available from: http://macyfoundation.org /docs/macy_pubs/2016_Conference_Summary_FINAL.pdf

[4] Fraher E, Spetz J, Naylor M. Nursing in a transformed health care system: New roles, new rules. Princeton: Robert Wood Johnson Foundation. 2015

[5] American Association of Colleges of Nursing. Essentials of baccalaureate education for professional nursing. Washington D.C.: American Association of Colleges of Nursing. 2008.

[6] Bouchaud M, Swan BA, Gerolamo A, et al. Accelerating design and transforming baccalaureate nursing education to foster a culture of health. Journal of Nursing Education and Practice. 2016; 6(11): 97-103. https://doi.org/10.5430/jnep.v6n11p97

[7] Cronenwett L, Sherwood G, Barnsteiner J, et al. Quality and safety education for nurses. Nursing Outlook. 2007; 55(3): 122-131. PMid:17524799 https://doi.org/10.1016/j.outlook. 2007 .02 .006
[8] Interprofessional Education Collaborative. Core competencies for interprofessional collaborative practice. Washington, DC: Interprofessional Education Collaborative. 2011.

[9] Maeshiro R, Evans C, Stanley J, et al. Using the clinical prevention and population health curriculum framework to encourage curricular change. American Journal of Preventive Medicine. 2011; 40(2): 232244. PMid:21238874 https://doi.org/10.1016/j.amepre.2 010.10 .030

[10] Giddens J, Brady D. Rescuing nursing education from content saturation: The case for a concept-based curriculum. Journal of Nursing Education. 2007; 46(2): 65-68. PMid:17315564

[11] Ahmed Z, Hutter L, Plaut J. Reflection in Higher Education ServiceLearning. Scotts Valley, CA: Learn and Serve America's National Service-Learning Clearinghouse. 2009.

[12] Kolb D. Experiential learning: Experience as the source of learning and development. Englewood Cliffs: Prentice Hall, Inc. 1984.

[13] Yancy K. Electronic portfolios: A decade into the 21st century. Peer Review. 2009; 11(1): 28-32. 